\title{
Lung sequestration: report of seven cases and review of 540 published cases
}

\author{
B SAVIC, F J BIRTEL, W THOLEN, H D FUNKE, AND R KNOCHE \\ From the Chirurgische Universitäts-Klinik 5300 Bonn, Vennsberg, W Germany
}

ABSTRACT We present an analysis of 400 intralobar and 133 extralobar sequestrations, six cases presenting intra- and extralobar sequestration simultaneously, five sequestrations of one whole lung, and two bilateral intralobar sequestrations.

This anomaly comprises $0 \cdot 15-6 \cdot 4 \%$ of all congenital pulmonary malformations. Usually the posterior basal segment is affected.

The aberrant artery in intralobar sequestration originated in $74 \%$ of all cases from the thoracic aorta, and in $14.8 \%$ there was more than one anomalous artery. The mean diameter of the aberrant arteries was 6:3-6.6 mm. Usually arteries with predominantly elastic fibres were found. Arteriosclerotic changes were common, even in children.

The venous return of the intralobar sequestration is, in $95.7 \%$ of all cases, via the pulmonary veins.

In $13.7 \%$ of all cases other congenital malformations were obscrved. Symptoms arose within the first decade of life in $37.2 \%$

Bronchography and retrograde arteriography are the mainstay of diagnosis. Sequestrations are not supplied by a bronchial artery.

Treatment of choice is operation as early as possible. Altogether seven operative deaths were reported, five of which were due to haemorrhage during operation.

Of the 133 extralobar sequestrations, $77 \cdot 4 \%$ were located between diaphragm and lower lobe. The arterial supply was provided by branches of the aorta. Some cases were supplied with venous blood by branches of the pulmonary artery. In six cases secondary changes, such as tuberculosis or carcinoma were found. In $60 \%$ of all the patients symptoms occurred within the first decade of life. Preoperative diagnosis was correct in only six cases. There were four postoperative deaths.

Bronchopulmonary sequestration is a relatively rare anomaly, which has been known for over 100 years (Rokitansky, 1861; Rektorzik, 1861). Despite this fact there are still some unanswered questions. Thus a review presented in 1963 by Biancalana listed as many as 40 hypotheses intended to provide an embryological explanation of its genesis.

The numerous published reports deal only with small numbers of cases. The divergences begin with nomenclature. In common with most authors, we have adopted the nomenclature proposed by Pryce (1946) and Pryce et al (1947) and accordingly mean by bronchopulmonary sequestration an area of lung, the parenchyma of which has no connection with the bronchial system, which is supplied by an aberrant artery arising from the aorta or one of its side branches, and which is drained as a rule by the pulmonary veins. A differentiation is made $\bar{N}$ between intralobar sequestrations, which share a o common pleura with the normal lung tissue, and $N$ extralobar sequestrations, which are separated N from the remaining lung tissue by a separate lining of pleura.

\section{Material and method}

This study is an analysis of 400 intralobar (in- 뭉

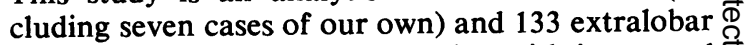
sequestrations, six cases presenting with intra- and $\mathbb{Q}$ extralobar sequestrations simultaneously, five $\frac{\varrho}{0}$ sequestrations of the whole of the lung, and two 
bilateral intralobar sequestrations published between 1862 and 1975 . Only reports on welldocumented cases were considered.

INTRALOBAR BRONCHOPULMONARY SEQUESTRATION The frequency of this anomaly varies between $0.15 \%$ and $1.7 \%$; in comparison, Coman et al (1973) quotes a figure of $6.4 \%$ for all congenital pulmonary anomalies.

The posterior basal segment is most often affected (table 1). In 16\% some of the lower lobe segments are affected, and in 5\% all of them. There is no specific sex distribution pattern with respect either to the occurrence of the anomaly or to its location.

In 373 of the cases described the origin of the supplying artery was indicated; in 276 cases it originated from the thoracic aorta (table 2). In 55 of these cases there was more than one anomalous artery, and in several cases the supplying artery was described as dividing before entering the parenchyma of the lung. A retro-oesophageal course of the anomalous artery was described on six occasions. In 206 case histories the diameter of the anomalous blood vessels was given. The mean diameter of the arteries originating in the thoracic aorta was $6.3 \mathrm{~mm}$ (160 quotes), and in the abdominal aorta $6.6 \mathrm{~mm}$ (46 quotes). The calibre of the vessels varied from 1-15 mm, although in one case an aneurysmal dilatation with a diameter of $25 \mathrm{~mm}$ was described. The diameters of the vessels did not depend on their number.

Table 1 Location of intralobar lung sequestration $(n=400)$

\begin{tabular}{lccr}
\hline Location & Right & Left & \multicolumn{1}{l}{ Total } \\
\hline Lower lobe & 164 & 227 & $391(97 \cdot 75 \%)$ \\
Upper lobe & 6 & 2 & $8(2 \cdot 00 \%)$ \\
Middle lobe & 1 & - & $1(0.25 \%)$ \\
\hline
\end{tabular}

Table 2 Origin of the supplying artery. (Percentages in parentheses)

\begin{tabular}{lll}
\hline Origin of arterial supply & $\begin{array}{l}\text { Intralobar } \\
\text { sequestration } \\
(n=373)\end{array}$ & $\begin{array}{l}\text { Extralobar } \\
\text { sequestration } \\
(n=91)\end{array}$ \\
\hline Aorta thoracica descendens & $276(73 \cdot 9)$ & $42(46 \cdot 1)$ \\
Aorta abdominalis & $70(18 \cdot 7)$ & $29(31 \cdot 6)$ \\
Aa intercostales & $12(3 \cdot 2)$ & $4(4 \cdot 4)$ \\
A pulmonalis & 0 & $5(5 \cdot 5)$ \\
A subclavia & $3(0 \cdot 8)$ & 0 \\
A anonyma & $3(0 \cdot 8)$ & $1(1 \cdot 0)$ \\
A thoracica interna & $3(0 \cdot 8)$ & 0 \\
A pericardiophrenica & $1(0 \cdot 2)$ & $3(3 \cdot 3)$ \\
A coeliaca & $4(1 \cdot 0)$ & $1 \quad(1 \cdot 0)$ \\
A lienalis & $1(0 \cdot 2)$ & $2(2 \cdot 2)$ \\
A gastrica sinistra & 0 & $2(2 \cdot 2)$ \\
Aorta thoracica ascendens & 0 & 1 \\
A suprarenalis & 0 & $1 \cdot 0)$ \\
\hline
\end{tabular}

Among 60 descriptions of the histological structure, arteries with predominantly elastic fibres (so-called pulmonary type) were found in most cases. In one case, in which the intralobular sequestration was supplied by three arteries originating in the thoracic aorta, two vessels of the elastic type and one of the muscular type were found. Often arteriosclerotic change, the extent of which increases with increasing age, is described, but pronounced arteriosclerotic changes were also found in children aged between 5 and 10 years (three cases).

The venous return of the sequestration is usually via the pulmonary veins; there were only 19 cases $(4.25 \%)$ in which the draining vessels emptied directly into the veins of the systemic circulation (table 3 ).

Macroscopically, the colour of the anomalous region is a pale greyish-red and is clearly differentiated from the healthy parenchyma. There is often adhesion between the pleura covering the sequestration and the diaphragm, mediastinum, or thoracic wall. At the point of entry of the arteries there is a slight depression, and this fact has led some workers to speak of a "hilus." The consistency of the sequestration varies between firm and elastic and "fleshy." Histologically, two main groups can be differentiated:

(1) the cystic-bronchiectatic form, which most often gives rise to symptoms, and

(2) the pseudotumorous form, which is considered to be relatively free from symptoms. We found this extremely rare variation in only six of the 400 cases.

A more exact analysis of 100 reports presenting detailed pathological findings showed that the bronchiectatic form of intralobar sequestration can be divided into three sub-groups: $(a)$ the solitary cystic form (28 cases), (b) the polycystic form (64 cases), and (c) the mixed cystic form (eight cases).

In three reports it is stated that cystic changes

Table 3 Venous return of the sequestration. (Percentages in parentheses)

\begin{tabular}{lll}
\hline Venous drainage & $\begin{array}{l}\text { Intralobar } \\
\text { sequestration } \\
(n=19)\end{array}$ & $\begin{array}{l}\text { Extralobar } \\
\text { sequestration } \\
(n=52)\end{array}$ \\
\hline V hemiazygos & $4(21 \cdot 0)$ & $20(38 \cdot 5)$ \\
V pulmonalis & 0 & $11(21 \cdot 1)$ \\
V cava inferior & $4(21 \cdot 0)$ & $6(11 \cdot 5)$ \\
V azygos & $5(26 \cdot 3)$ & $4(7 \cdot 7)$ \\
V intercostalis & $3(15 \cdot 7)$ & $1(1 \cdot 9)$ \\
V cava superior & $3(15 \cdot 7)$ & 0 \\
V portae & 0 & $4(7 \cdot 7)$ \\
To abdominal vessels & 0 & $5(9 \cdot 6)$ \\
V suprarenalis & 0 & 1 \\
\hline
\end{tabular}


were seen immediately after birth. In $18 \%$ of the cases bronchiectasis was observed in the neighbouring parenchyma (histological findings are listed in table 4). On six occasions there was tuberculous disease in the sequestration and in an isolated case of a 44-year-old woman, despite the fact that there was no connection with the bronchial system, Nocardia mycelium was found within the sequestration (Charbonneau et al, 1967).

In 55 of the patients $(13.7 \%)$ other congenital anomalies were observed (table 5).

The first symptoms occurred before the age of 10 in $37.2 \%$ of the patients. In $15.5 \%$ of the cases, the disease remained asymptomatic and was discovered by chance. The commonest symptoms were cough, expectoration, and recurrent attacks of pneumonia, all of which become more severe with time. Physical examination showed no particular signs, although cyanosis, clubbed fingers, asymmetry of the thorax, rib anomalies, and funnel chest sometimes occurred. In $4 \%$ of the cases pleurisy and pleural effusions were observed.

For the establishment of the diagnosis radiographic findings (table 6) and bronchoscopy are

Table 4 Histological findings

\begin{tabular}{lcc}
\hline Histological findings & $\begin{array}{l}\text { Intralobar } \\
\text { sequestration } \\
(n=100)\end{array}$ & $\begin{array}{l}\text { Extralobar } \\
\text { sequestration } \\
(n=50)\end{array}$ \\
\hline Alveoli & 8 & 31 \\
Ciliated epithelium & 41 & 0 \\
Squamous epithelium & 20 & 38 \\
Cylindrical epithelium & 40 & 32 \\
Bronchi & 45 & 23 \\
Glands & 7 & 26 \\
Cartilage & 10 & 16 \\
Muscle & 5 & 15 \\
Nerves & 3 & 27 \\
Elastic fibres & & \\
Fibrous tissue & 28 & 3 \\
Vessels with thickened intima & 6 & 4 \\
Epitheloid cells & & 23 \\
Giant cells & & 6 \\
Lymphocytes & 80 & \\
Inflammation & & \\
\hline
\end{tabular}

Table 5 Anomalies concomitant with intralobar lung sequestration $(n=400)$

\begin{tabular}{lll}
\hline Anomaly & \multicolumn{2}{l}{$\begin{array}{l}\text { No (\%) } \\
\text { of cases }\end{array}$} \\
\hline Oesophagobronchial diverticulum & 15 & $(3 \cdot 7)$ \\
Diaphragmatic hernia & 12 & $(3 \cdot 0)$ \\
Deformities of skeletal system & 16 & $(4 \cdot 0)$ \\
Heart anomalies, anomalies of & & \\
pericardium, and great vessels & 8 & $(2 \cdot 0)$ \\
Renal anomalies & 3 & $(0 \cdot 7)$ \\
Cerebral anomalies & 1 & $(0 \cdot 2)$ \\
Total & 55 & $13 \cdot 7$ \\
\hline
\end{tabular}

Table 6 Radiographic findings in intralobar lung sequestration $(n=100)$

\begin{tabular}{lr}
\hline Cystic area & 52 \\
Fluid level & 26 \\
Homogeneous shadow & 32 \\
Inhomogeneous shadow & 16 \\
Retrocardiac localisation & 2 \\
Multiple fluid levels & 4 \\
First radiographic examination negative & 2
\end{tabular}

not very helpful; however, bronchography almost $\overrightarrow{\vec{x}}$ always shows the lack of connection to the $\dot{\omega}$ bronchial system and the displacement of the bronchi in the neighbouring lobes (table 7). The $\overrightarrow{0}$ anomalous vascular supply can most reliably be seen by means of retrograde aortography, a procedure that was described in 39 cases. Three cases $\vec{T}$ were reported in which the aberrant artery was $\mathbb{D}$ not identified by angiography and was first recognised during surgery. Angiocardiography showed the atypical artery in 15 cases and failed to do so in five. In a report of our own (Savic et al, 1971) we were able to show by bronchial arteriography. that the sequestered pulmonary parenchyma was not supplied by the bronchial arteries. Scintigraphy of the lungs has brought a real advance in diagnosis (Payfa, 1968).

Table 8 lists the preoperative diagnoses in $100 \stackrel{8}{\mathbb{Q}}$ patients. We found 391 reports of surgical treat- $\overrightarrow{\vec{A}}$ ment. Four patients died before the planned $\frac{3}{3}$ surgery could be carried out, four patients refused

Table 7 Bronchographic findings in intralobar lung sequestration $(n=100)$

\begin{tabular}{lr}
\hline No filling & 61 \\
Displacement & 30 \\
Bronchiectasis & 18 \\
Bronchial anomalies & 9 \\
Communication of bronchial & \\
$\quad$ tree with the sequestration & 14 \\
No pathological findings & 5 \\
\hline
\end{tabular}

Table 8 Preoperative diagnosis of intralobar lung sequestration $(n=100)$

$\begin{array}{lr}\text { Intralobar lung sequestration } & 39 \\ \text { Tentative diagnosis of intralobar } & \\ \quad \text { lung sequestration } & 8 \\ \text { Pulmonary emphysema } & 29 \\ \text { Pulmonary abscess } & 9 \\ \text { Bronchiectasis } & 9 \\ \text { Pulmonary tumour } & 6 \\ \text { Bronchial adenoma } & 2 \\ \text { Neurinoma } & 2 \\ \text { Pericardial cyst } & 1 \\ \text { Echinococcus } & 2 \\ \text { Tuberculosis } & 6 \\ \text { Empyema } & 2 \\ \text { Diaphragmatic hernia } & 1 \\ \text { Aortic aneurysm } & 1 \\ \text { Spontaneous pneumothorax } & 1\end{array}$


operation, and in one case, after full investigation, no surgical procedure was performed. Information on the nature of the operation is given in table 9. Among the postoperative complications there were four cases of haemothorax, which necessitated reoperation in three cases, nine cases of empyema, four of bronchopleurocutaneous fistula and one bronchopleural fistula. Seven intraor postoperative deaths were reported. Five patients died of haemorrhage when, after the accidental severance of the aberrant artery, the bleeding could not be controlled.

EXTRALOBAR BRONCHOPULMONARY SEQUESTRATION We found 133 well-documented cases of extralobar sequestration. In $77.4 \%$ of the cases the sequestration was located between the diaphragm and the lower lobe (table 10). Distribution and location were identical in both sexes.

The arterial supply to the sequestration was provided by branches of the aorta (table 2); in seven cases double arteries originated in the thoracic aorta, and in four cases in the abdominal aorta. In one case each, three and four arteries of supply originating in the thoracic aorta were described. Five cases were supplied with venous blood by a side branch of the pulmonary artery, the venous return being effected by the pulmonary veins. In four cases the aberrant tissue was supplied by several arteries of different origins, the following combinations being described: left

Table 9 Surgical procedure in treatment of intralobar lung sequestration $(n=391)$

\begin{tabular}{lr}
\hline Method & No $(\%)$ of cases \\
\hline Lobectomy & $286(71 \cdot 5)$ \\
Segmental resection & $52(13 \cdot 0)$ \\
Cystectomy & $14(3 \cdot 5)$ \\
Pneumonectomy & $4(1 \cdot 0)$ \\
Bilobectomy & $7(1 \cdot 7)$ \\
Bisegmental resection & $2(0 \cdot 5)$ \\
Operation refused & $3(0 \cdot 7)$ \\
No operation & $1(0 \cdot 2)$ \\
No information obtained & $26(6 \cdot 5)$ \\
\hline
\end{tabular}

Table 10 Localisation of extralobar lung sequestration $(n=133)$. (Percentages in parentheses)

\begin{tabular}{lllcr}
\hline Localisation & Right & Central & Left & Total \\
\hline Basal & 17 & & 86 & $103(77 \cdot 4)$ \\
Between upper & & & 5 & $6(4 \cdot 1)$ \\
$\quad$ and lower lobe & 1 & & 2 & $2(1 \cdot 5)$ \\
Paracardiac & 2 & 2 & $6(4 \cdot 1)$ \\
Mediastinal & 2 & 3 & 2 & $(2 \cdot 2)$ \\
Infrapericardial & & & 10 & $11(8 \cdot 2)$ \\
Infradiaphragmatic & 1 & & $105(78 \cdot 9)$ & \\
Abdominal & $23(17 \cdot 2)$ & $5(3 \cdot 7)$ & $1 \cdot 5)$ \\
Total & & & & \\
\hline
\end{tabular}

gastric artery with the abdominal aorta, left gastric artery with the splenic artery, the descending aorta with a rudimentary branch of the pulmonary artery, and, finally, the left gastric artery together with the coeliac trunk. In 21 cases the route by which the supplying artery from below the diaphragm reached the sequestration by way of the hiatus aorticus, hiatus oesophageus, or a congenital defect in the diaphragm was described. In general, the artery enters the pulmonary parenchyma near the draining vein.

The greatest diameter of the artery described was $12 \mathrm{~mm}$, the smallest $1 \mathrm{~mm}$. In 12 cases only was useful information given as to the histological structure of the artery. In nine cases an artery of the "pulmonary type" and in three cases one of the "systemic type" was found. On three occasions arteriosclerosis was described in the supplying artery.

On 14 occasions the venous return was effected via a pulmonary vein into the left heart, this group containing four cases in which the arterial supply was secured via a branch of the pulmonary artery.

The extralobar sequestration is often attached to parts of the mediastinum, the diaphragm, or the stomach-sometimes even fistulous connections between the bronchi and the stomach or the oesophagus are described-by means of an "offshoot," which contains the bundle of vessels and often also nerves and blindly ending bronchi. In $3.7 \%$ of the cases the sequestration was connected with the lower lobe by means of a "cord" of tissue; in 60 cases the various forms of connection of the sequestration with the surrounding tissue were described in detail.

In 42 patients we found accurate data as to the size of the sequestration, the largest being found in a 26 -year-old man $(15 \times 8 \times 6 \mathrm{~cm})$, a 30 -year-old woman $(12 \times 11 \times 5 \mathrm{~cm})$, and in a 16-year-old boy $(11 \times 7.5 \times 6 \mathrm{~cm})$; Robertson (1973) reported the case of a neonate in which the sequestration occupied two-thirds of the left pulmonary zone.

The extralobar sequestration is usually pyramidal in shape, less often round or oval; its colour is grey, grey-red, or dark red. The surface is homogeneous and shiny and only very rarely can cysts be recognised under the surface. The consistency is firm and is described as being like that of liver or spleen. On four occasions a lobed form of sequestration was found. As a rule, histological examination showed atelectatic, embryonal, partly dysplastic, partly hyperplastic lung tissue. In 50 cases nine were solitary cysts, 29 were polycystic, and 12 had no cysts. In six cases there were tuberculous changes in the pulmonary par- 
enchyma. In addition hyaline membranes were mentioned and, on one occasion, a keratinising squamous cell carcinoma was described. In 56 cases $(58.9 \%)$, apart from the lung anomalies, further malformations were found (table 11), five cases manifesting multiple anomalies (table 5). In $60 \%$ of the patients a wide range of different symptoms occurred before the age of 10 years; in $10 \%$ of the cases the sequestration was discovered "by accident." The oldest patient in whom an extralobar sequestration was found was an 81year-old woman. Assessment of the value of the various diagnostic methods is similar to that for intralobar sequestration. One case is known in which, over 20 years, no change occurred in the radiological appearance.

Sixty-six of the 133 cases underwent surgery. In the remaining 67 patients the diagnosis was established at necropsy. A correct preoperative diagnosis was made in six cases only; in the differential diagnosis the possibility of a sequestration was considered somewhat more often. Frequently, an accompanying diaphragmatic hernia was the actual indication for operation, and the sequestra-

Table 11 Anomalies concomitant with extralobar lung sequestration $(n=56)$. (Percentages in parentheses)

\begin{tabular}{lr}
\hline Diaphragmatic herniae (total) & $36(27 \cdot 6)$ \\
Herniae with diaphragmatic defects & $19(14 \cdot 2)$ \\
Relaxation of the diaphragm & $5(3 \cdot 7)$ \\
Lung anomalies & $13(9 \cdot 7)$ \\
Oesophago-tracheal fistula & $2(1 \cdot 5)$ \\
Epiphrenic diverticulum & $3(2 \cdot 2)$ \\
Vitium cordis & $6(4 \cdot 5)$ \\
Perdicardial anomalies & $4(3 \cdot 0)$ \\
Funnel chest & $1(0 \cdot 7)$ \\
Oesophageal duplication & $1(0 \cdot 7)$ \\
Megacolon & $1(0 \cdot 7)$ \\
Other anomalies & $11(8 \cdot 3)$ \\
Total & 84 \\
\hline
\end{tabular}

tion was found during the operation. Four post- $\overrightarrow{\vec{s}}$ operative deaths were recorded; of 30 neonates 0 who presented with a sequestration, 23 died shortly $\overline{0}$ after diagnosis, and most had multiple anomalies.

Table 12 presents a summary of the features of the cases with a combination of intralobar and extralobar sequestration.

\section{Discussion}

We have no new proposals concerning aetiology. It $\overrightarrow{\vec{x}}$ seems that the sequestration is a region of lung $\underset{\omega}{\dot{\omega}}$

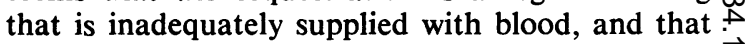
this reduced perfusion is the cause of the $\overrightarrow{0}$ occurrence of an atypical vessel. The fact that the intralobar and extralobar forms can be present $\stackrel{\circ}{\triangle}$ simultaneously suggests that the two forms have $\vec{T}$ a common embryopathogenic basis. The propensity $\mathbb{D}$ to develop this anomaly does not seem to be hereditary; there are no reports of bronchopulmonary sequestration in any close relatives. Nor have any typical chromosome constellations become known (Flye, 1972).

Intralobar sequestration shows no preference for one or other side of the thorax; $80 \%$ of the extralobar forms occur on the left.

In both forms multiple arterial supply was found in about the same percentage of cases $(15 \%) \stackrel{\mathbb{D}}{\mathcal{D}}$ -an observation that is certainly of value for the $\overrightarrow{\vec{A}}$ surgeon's tactical approach. The calibre of the $\frac{3}{3}$ supplying vessels can be considerable, particularly in the extralobar form, in which vessels of up too $6 \mathrm{~mm}$ are found.

The extent of the sequestration is very variable. Using 42 accurate reports with respect to size we calculated the volume of the extralobar sequestra- $\frac{0}{0}$ tion and discovered a correlation between size and 3 . age. While in the newborn and in children an un- $\delta$ correlated scatter is found, between the ages of $₹$

Table 12 Combination of intra-and extralobar lung sequestration (six cases)

\begin{tabular}{|c|c|c|c|c|c|}
\hline \multirow[t]{2}{*}{ Age } & \multirow[t]{2}{*}{ Sex } & \multicolumn{2}{|l|}{ Localisation } & \multirow[t]{2}{*}{ Arterial supply } & \multirow[t]{2}{*}{ Notes } \\
\hline & & $E L S$ & $I L S$ & & \\
\hline 16 & $\mathbf{F}$ & Right LL & Right LL & Intercostal artery to ESL & $\begin{array}{l}\text { Connection of ELS and ILS by vascular cord, } \\
\text { venous drainage to } \mathrm{v} \text { pulmonalis }\end{array}$ \\
\hline 15 & $\mathbf{M}$ & Left sub-diaphragmal & Left LL & Aorta abd. to ILS & $\begin{array}{l}\text { Open connection from ELS to ILS via hiatus } \\
\text { oesophageus }\end{array}$ \\
\hline 2 & $\mathbf{M}$ & Mediastinal & Right LL & $?$ & Eventration of diaphragm \\
\hline 24 & $\mathbf{M}$ & Paravertebral & Left LL & ${ }^{2}$ & $\begin{array}{l}\text { In ILS chronic inflammation giant cells, central } \\
\text { caseous necrosis; in ELS cysts filled with mucus, } \\
\text { calcification }\end{array}$ \\
\hline$?$ & $?$ & Mediastinal & Right LL & $\begin{array}{l}\text { Anomalous vessels from } \\
\text { A pulmonalis to ILS }\end{array}$ & ELS with extension to oesophagus \\
\hline 15 & $\mathbf{F}$ & Whole UL right & $\begin{array}{l}\text { Right LL } \\
\text { and ML }\end{array}$ & $\begin{array}{l}\text { From aorta abdom via } \\
\text { diaphragmatic hernia to } \\
\text { ILS and ELS }\end{array}$ & $\begin{array}{l}\text { Diaphragmatic hernia, hypoplastic A pulmonalis; } \\
\text { intraoperative death caused by ventricular } \\
\text { standstill after severe bleeding }\end{array}$ \\
\hline
\end{tabular}

ELS = Extralobar lung sequestration; ILS = Intralobar lung sequestration; LL = Lower lobe; UL=Upper lobe; $M L=M i d d l$ lobe. 
15 and 35 the size of the lesion is greater than the mean, and between the ages of 36 and 81 this mean size is not attained. This suggests that an extralobar sequestration increases in size up to the age of 35 , after which it begins to shrink.

The intralobar sequestration is much less often associated with other anomalies (14\%) than is the extralobar form (about 50\%). The anomalies found in the extralobar form are usually more serious and often occur in combination. There is often a history of abnormal pregnancy in the mother.

There is no specific pattern of symptoms for this condition-in many cases the symptoms that lead to further investigation are due to accompanying diseases or other anomalies.

If a bronchopulmonary sequestration is suspected bronchography and retrograde aortography are the essential examinations to confirm the diagnosis and to avoid intraoperative difficulties due to varying blood supply.

The full bibliography of 178 references may be obtained from Dr B Savic.

\section{References}

Biancalana, L (1963). Die lungenzysten. Thoraxchirurgie, 11, 511-531.

Charbonneau, R V, Jodoin, G, and Bernier, J (1967). Une lesion congénitale vasculaire pulmonaire: la sequestration. Union Medicale du Canada, 96, 158164.

Coman, C, Stan, A, Georgescu, G, Dobrinov, A, and
Dimitriu, M (1973). Les problèmes actuels des sequestrations pulmonaires intra- et extra-lobaires. Le Poumon et le Coeur, 29, 211-220.

Flye, M W, and Robert, J I (1972). Extrałobar pulmonary sequestration with esophageal communication and complete duplication of the colon. Surgery, 71, 744-752.

Payfa, M, Muteta, J F, van Thiel, E, Leblanc, F, and Vanderhoeft, $P$ (1968). Séquestration pulmonaire. Acta Tuberculosea et Pneumologica Belgica, 59, 403-412.

Pryce, D M (1946). Lower accessory artery with intralobar sequestration of the lung. Journal of Pathology and Bacteriology, 58, 457-467.

Pryce, D M, Sellors, T H, and Blair, L G (1947). Intralobar sequestration of lung associated with an abnormal pulmonary artery. British Journal of Surgery, 35, 18-29.

Rektorzik, E (1861). Ueber accessorische lungenlappen. Wochenblatt der Zeitschrift der Kaiserlichen und Koniglichen Gesellschaft der Arzte in Wien, 17, 4.

Robertson, S (1973). Extralobar lung sequestration in a newborn infant. An unusual cause of respiratory distress. Central A frican Journal of Medicine, 19, 74-76.

Rokitansky, C von (1861). Lehrbuch der Pathologischen Anatomie, p 44. Braumüller, Wien.

Savic, B, Paquet, K J, and Wessel, W (1971). Nosologische, pathologisch-anatomische, diagnostische und therapeutische gesichtspunkte zum krankheitssbild der intralobären lungensequestration. Thoraxchirurgie, 19, 451-459.

Requests for reprints to: Priv Doz Dr B Savic, 53Bonn-1, Luisenstrasse 6. 